\title{
ON THE IMPACT OF IEEE 802.16 BANDWIDTH REQUEST-GRANT MECHANISMS ON TCP
}

\author{
Globecom 2010
}

Yubo Yang, Andrés Arcia-Moret, Nicolas Montavont, David Ros 


\section{Agenda}

$\square$ Motivation

$\square$ Background

$\square$ Bandwidth Perception System for Best Effort Traffic

$\square$ Performance Model

$\square$ Simulation Results

$\square$ Conclusion \& Future Work 


\section{Motivation}

$\square \mathrm{TCP}$

a Controls about $90 \%$ of the 200000 terabytes crossing the internet per second.

$\square$ Transports up to $75 \%$ of on-demand and live streaming traffic.

$\square$ IEEE 802.16 Standards

$\square$ Next generation Wireless broadband solution

$\square$ Provide high speed internet access for mobile and residential users.

$\square$ In IEEE 802.16 networks, Uplink traffic also has significant impact on downlink TCP traffic.

$\square$ ACKs that regulate TCP traffic

Data packets that cause HoL blocking of ACKs. 


\section{TCP over WiMAX Networks}

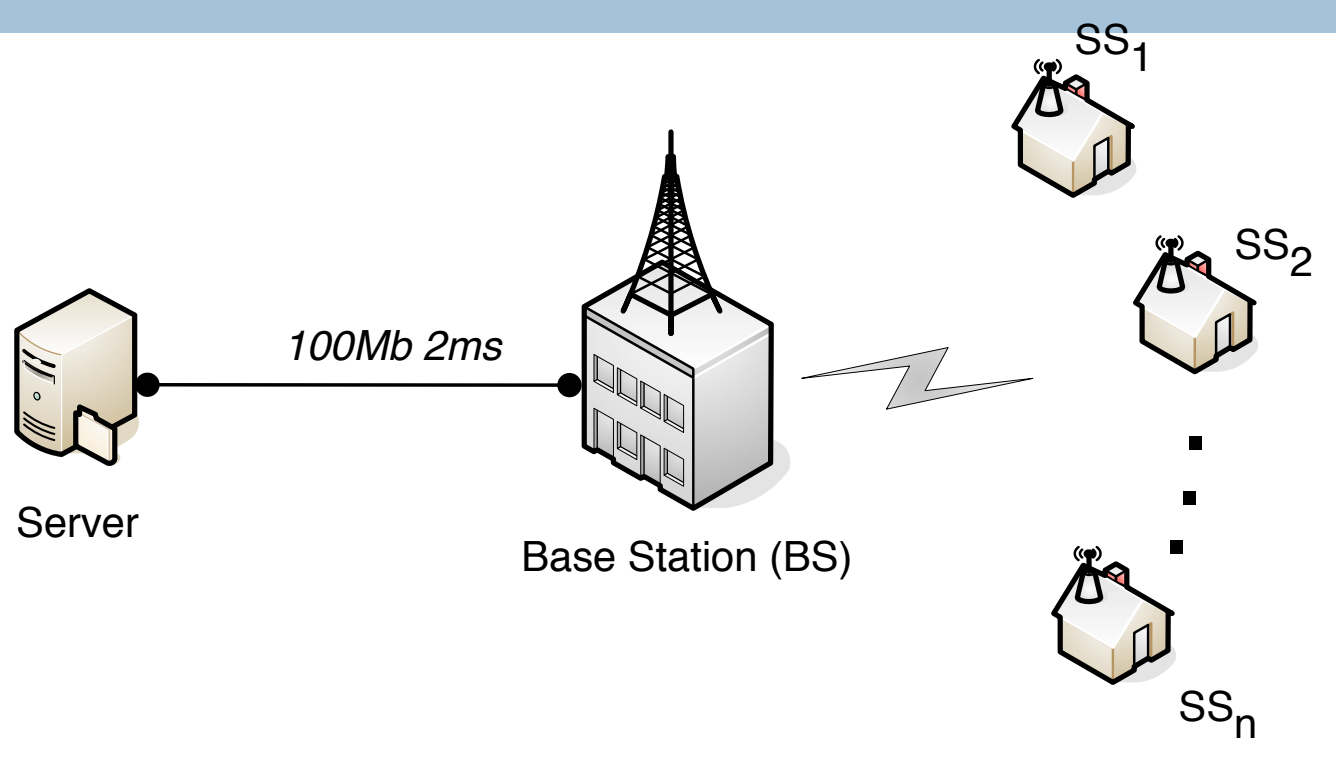

$\square$ Point to Multipoint topology as in $802.16 \mathrm{~d}$ and $802.16 \mathrm{e}$

$\square$ TCP traffic transported by BE Class of Service

- Uses contention based bandwidth requesting

$\square$ Bandwidth Control:

口 Downlink by central BS scheduler

口 Uplink Mixed Scheduler One Part Controlled by SS another by BS 


\section{IEEE 802.16 Frame}

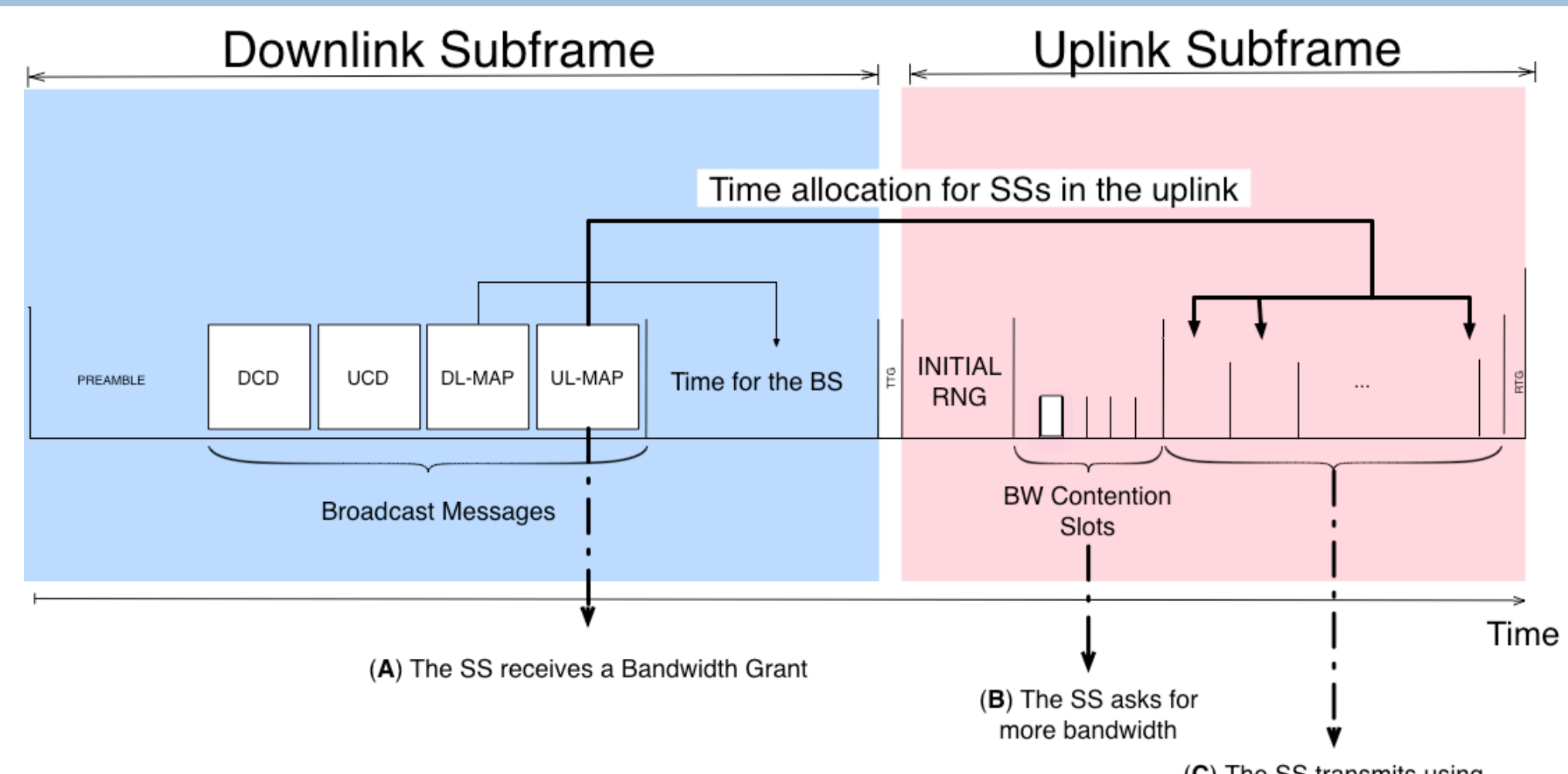

$\square \quad$ The BRGM is mainly used for Best-Effort traffic, and is a compound of:

(A) The bandwidth needs perception at the BS driven by the processing of $B R-R E Q$.

(B) The contention period to pass the BW-REQs

(C) The administration of the granted bandwidth at the SS. 


\section{Uplink Bandwidth REQUEST-GRANT Scheme}

a) 'Data and ACK Packets arrive in SSs' CID queue

b) SSs contend to transmit BW-REQ packets to BS.

c) Uplink Bandwidth Perception: BS processes received BW-REQs and calculates the bandwidth needs.

d) BS allocates uplink bandwidth according to the perceived bandwidth demand of SSs. 


\section{Bandwidth Perception at BS}

$\square$ Previous work bandwidth perception schemes

口 RPG: Reset per grant

- BS reset bandwidth perception to zero after granting

口 DPG: Decrease per grant

- BS decrease bandwidth perception after granting

$\square$ DDA: Decrease at data arrival.

- BS decrease bandwidth perception after receiving uplink data

- BS set bandwidth perception immediate after receiving BW-REQ packet 


\section{Getting out of synchronization-RPG}

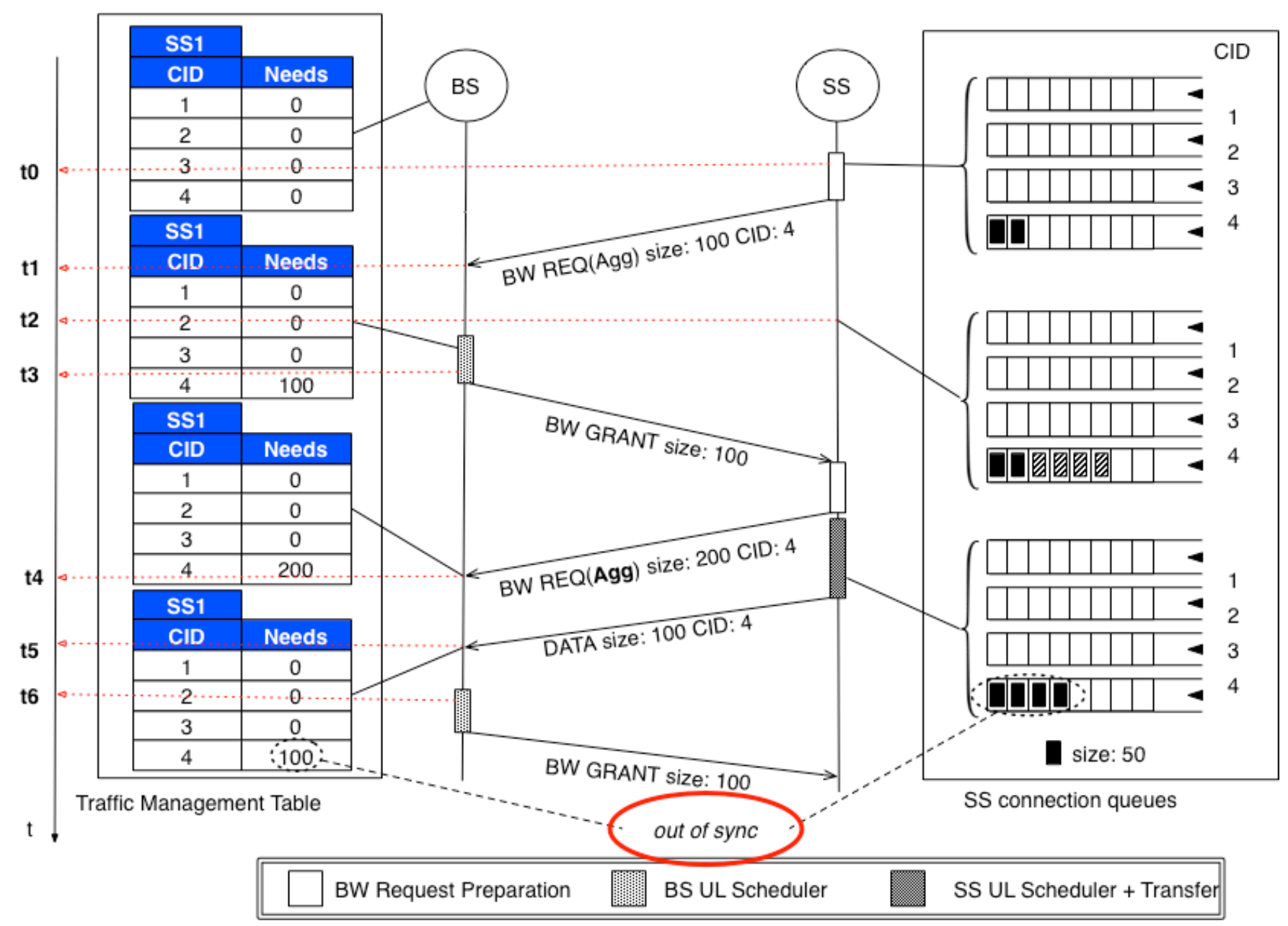




\section{Get out of synchronization-DPG}

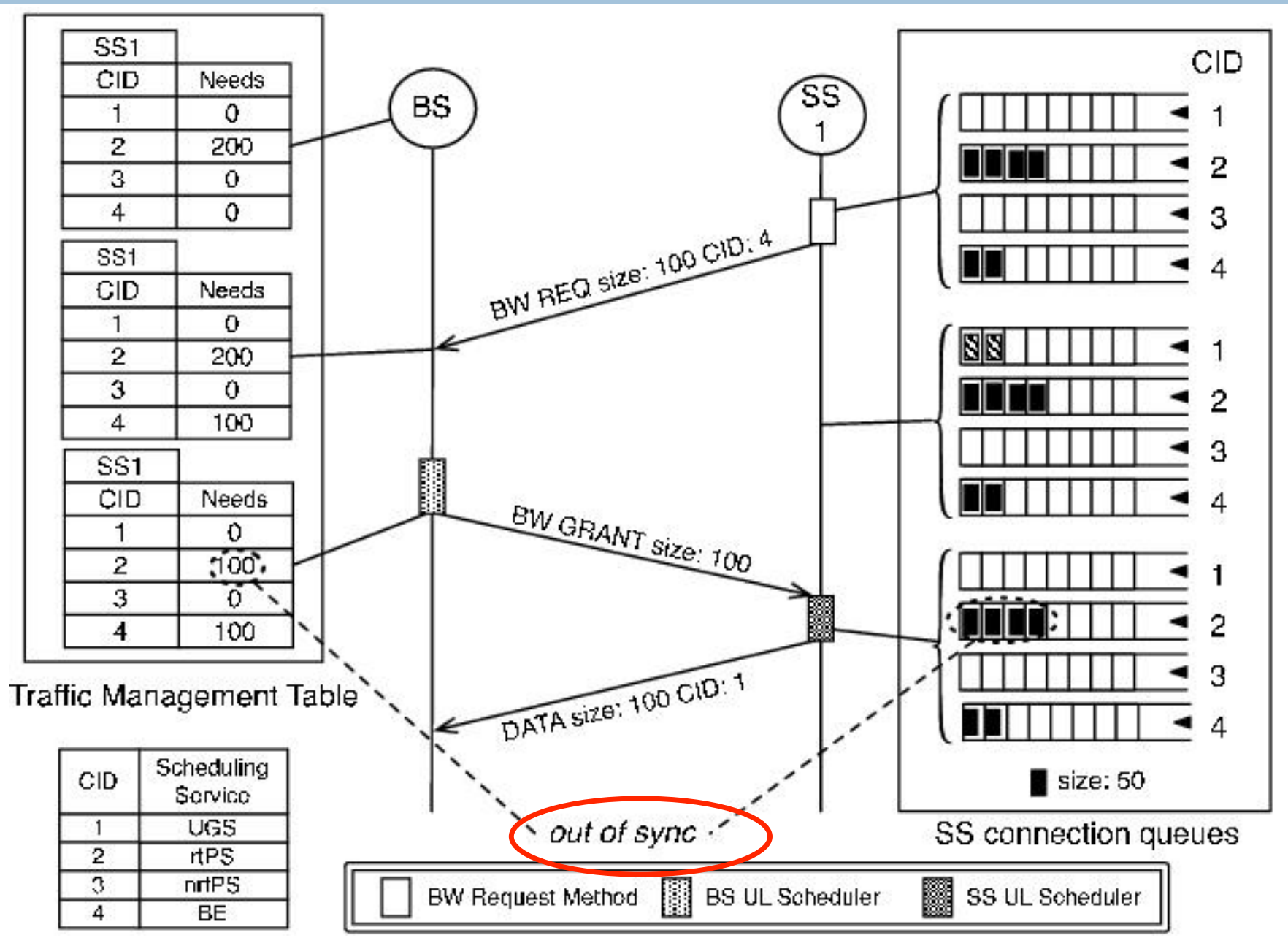




\section{Get out of synchronization-DDA-i}

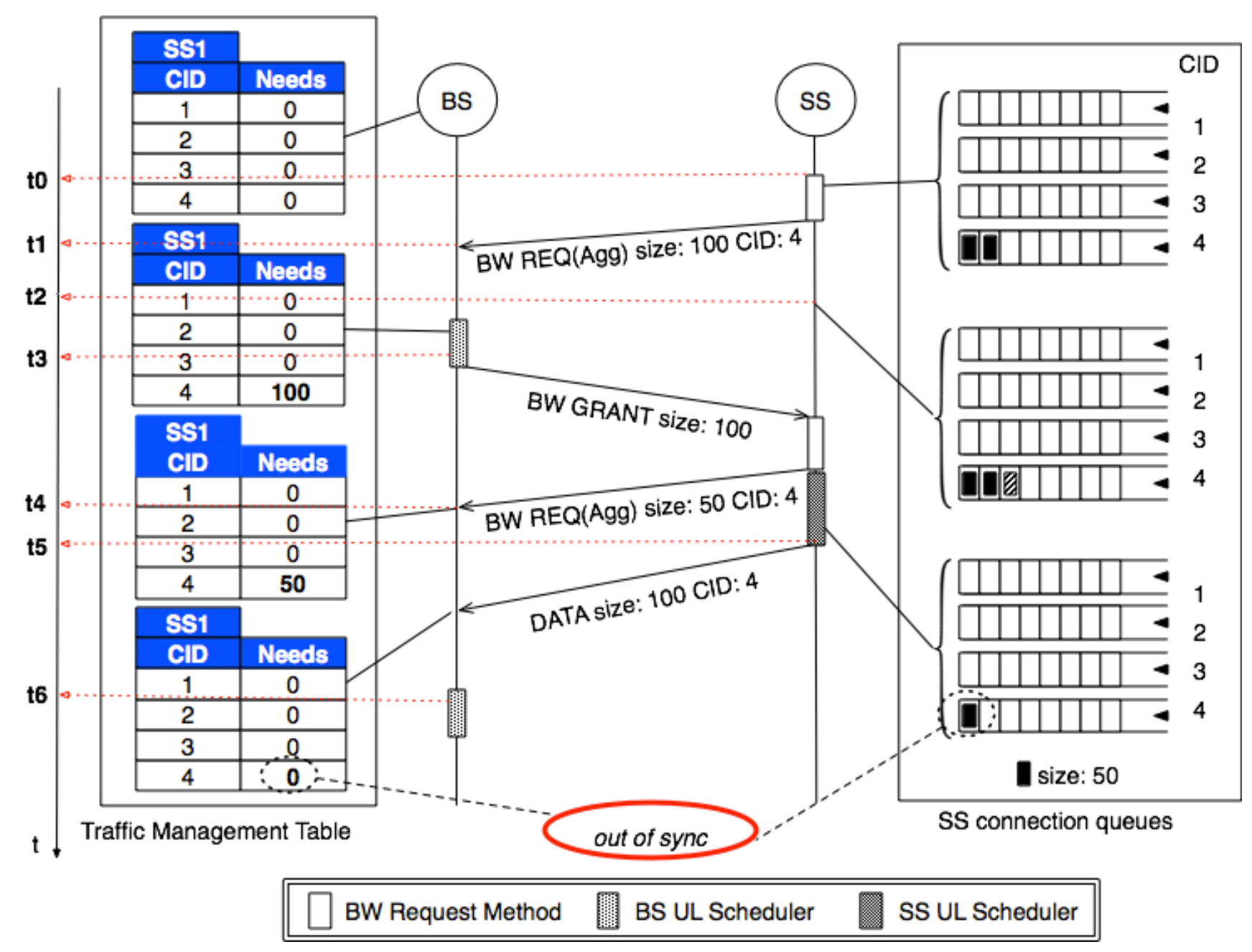




\section{Proposed bandwidth perception management: DDA-d}

$\square$ Main idea

$\square$ BW-REQs are delayed until the end of the frame to be processed.

$\square$ Perception of the BW should adapt to the dynamical demand/use of BW by SSs. 


\section{Proposed bandwidth perception management:}

\section{DDA-d}

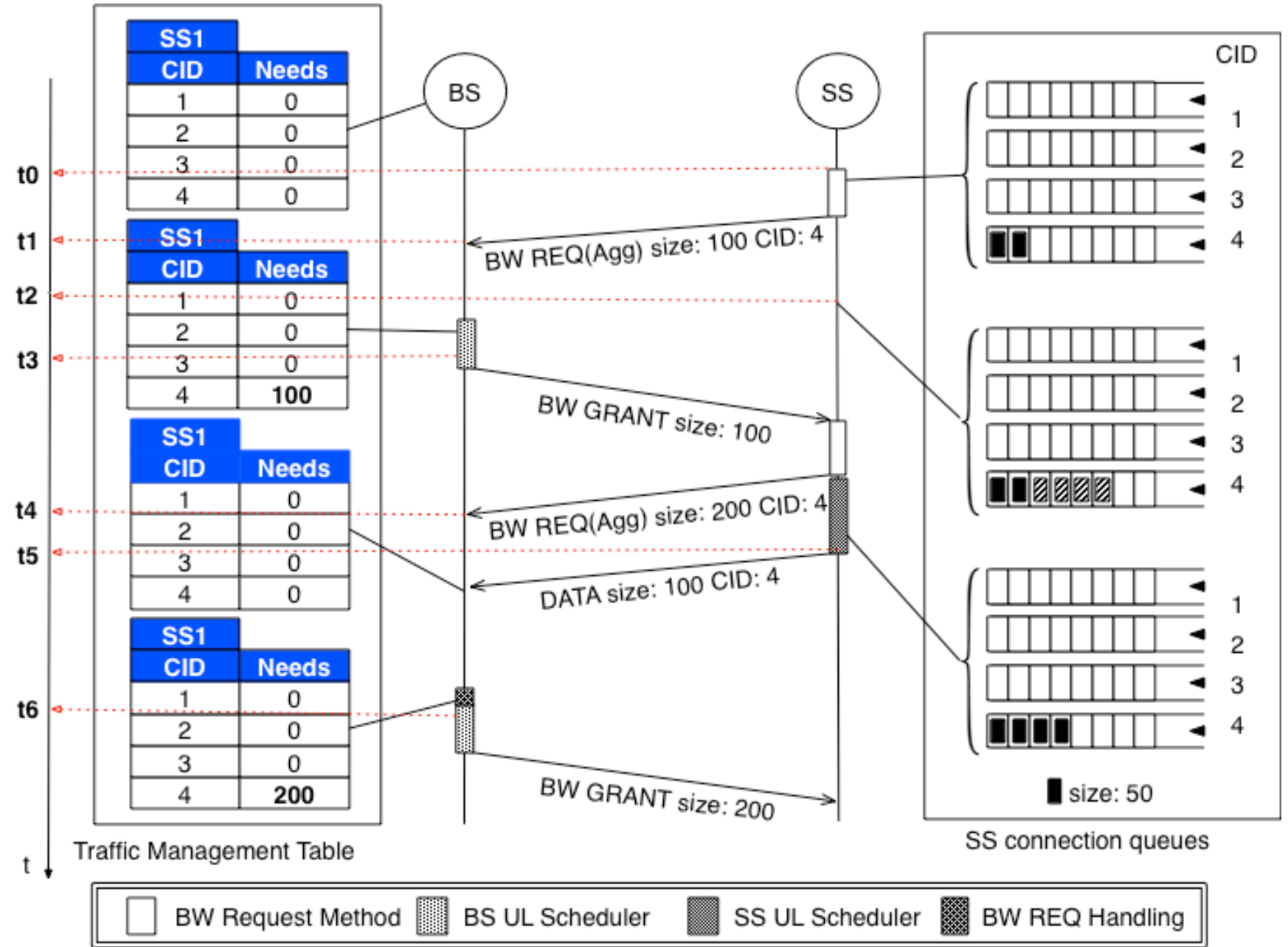




\section{Scenario Configuration}

$\square$ WiMAX

口 Point to Multipoint Topology

口 DL:UL ratio is set to $1: 1$

口 Frame duration is set to $5 \mathrm{~ms}$

$\square \mathrm{TCP}$

$\square$ Randomly launched long-lived TCP NewReno flows

a Segment size 1000 Bytes

$\square$ Delayed ACKs

口 Simulation time: $1000 \mathrm{sec}$

ㅁ 10 repetitions for every point 


\section{Simulation Results}

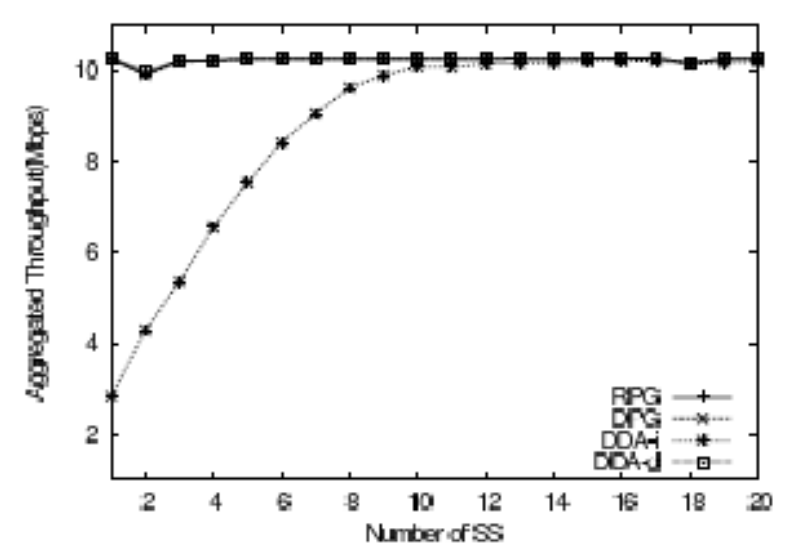

(a) Aggregated Throughput

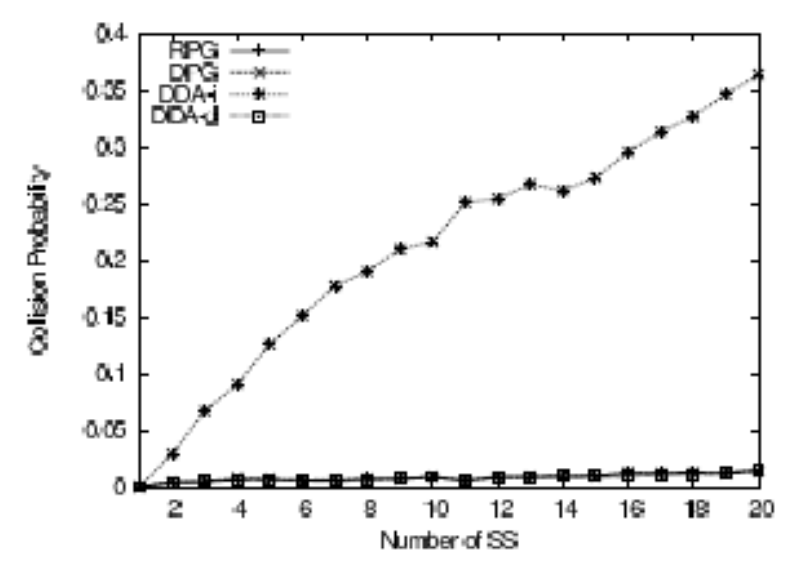

(b) BW-REQ Collision Probability

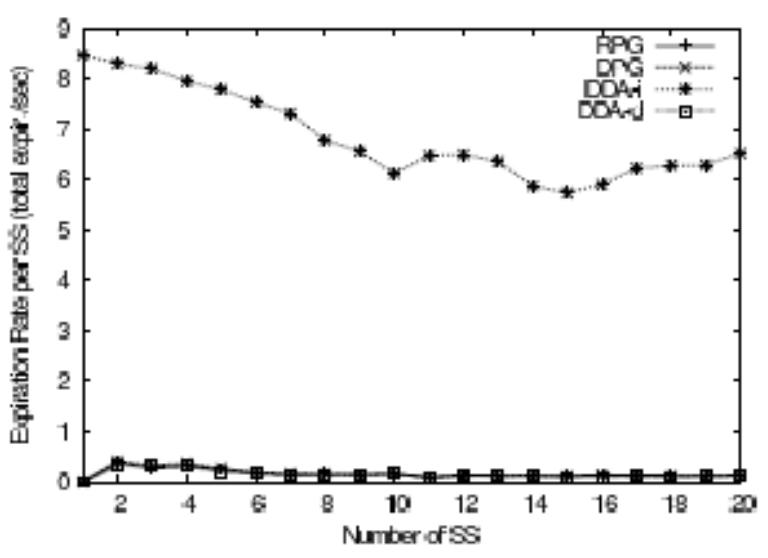

(c) T16 Expiration Rate per SS

Figure 9. Download-only traffic scenario, using exclusively aggregate requests (BW-REQs) for asking for uplink bandwidth.

$\square$ Downlink performance:

- Maximum throughput limited by the correct treatment of BWREQ.

$\square$ Unnecessary BW-REQ generation due to wrong $B W$ needs perception

口 Significant number of episodes BW concession deadlock. 


\section{Performance Model}

Our model aims at:

$\square$ Modeling the effect of the desynchronization of bandwidth perception

$\square$ Finding an expression for TCP throughput considering:

- Queve size at the BS

- Different number of SSs

- Variations on T16 


\section{Modeling Uplink Delay (1/5)}

$\square$ Uplink delay depends on passing the BW-REQ, which depends in turn on the BW-perception scheme

$\square$ Let's define $q$ as a measure for the desynchronization, i.e., a probability of being in such state. The probability of failure a single BW-REQ is:

$$
p_{f}=p+(1-p) q
$$

$\square$ The probability of a BW-REQ being successfully received at the $\mathrm{i}^{\text {th }}$ attempt:

$$
p_{f}^{i-1}\left(1-p_{f}\right)
$$




\section{Modeling Uplink Delay (2/5)}

$\square$ Thus, the average number of transmissions of a single successful $B W-R E Q$ is:

$$
\begin{gathered}
N_{t x}=\sum_{i=1}^{M} i p_{f}^{i-1}\left(1-p_{f}\right)+M p_{f}^{M} \\
N_{t x}=\sum_{i=1}^{M} p_{f}^{i-1}
\end{gathered}
$$

Being $M$ the maximum number of retransmissions. 


\section{Modeling Uplink Delay (3/5)}

$\square$ Assuming that a collision has the same probability to happen on any slot, and $T_{f}$ frame duration in which there are $\mathbf{n}$ slots for contention. The avg. number of slots for a successfully received BW-REQ:

$$
N_{s, i}=\frac{n T_{16}}{T_{f}}(i-1)+\frac{W_{0}}{2}\left(2^{i}-1\right)
$$

$\square$ Thus, the avg. number of waiting slots until the end of a single contention process is:

$$
N_{s}=\sum_{i=1}^{M}\left(p_{f}^{i-1}\left(1-p_{f}\right) N_{s, i}\right)+p_{f}^{M}\left(\frac{n T_{16}}{T_{f}} M+\frac{W_{0}}{2}\left(2^{M}-1\right)\right)
$$




\section{Modeling Uplink Delay (4/5)}

$\square$ The probability of transmitting a successful BW-REQ in a given slot:

$$
p_{t r}=\frac{N_{t x}}{N_{s}+T_{i d l e}}
$$

$\square$ Finally, we obtain $\mathbf{N}_{\mathrm{s}}$ and therefore the Uplink Delay:

$$
E\left[D_{u}\right]=\frac{N_{s} T_{f}}{n}
$$




\section{Modeling Downlink Delay}

$\square$ Given $\mathbf{r}_{\mathbf{k}}$ the sending rate for user $\mathbf{k}, \mathbf{N}$ the number of active $S S, P_{1}$ the packet size and $Q_{B S}$ the $B S$ queve length. We can calculate the expectation as follows:

$$
E\left[D_{d}\right]=\frac{P_{l}}{r_{k} / N} \frac{Q_{B S}}{2}
$$

And the expectation of the maximum window size:

$$
N_{C W}=\frac{Q_{B S}}{2}+\frac{r_{k}}{N P_{l}}\left(D_{u}+D_{\text {wired }}\right)
$$

$\square$ Also, the probability of a single packet loss is (b is the delayed ack factor):

$$
p_{\text {lost }}=\frac{1}{\frac{3}{4} b N_{C W}\left(\frac{N_{C W}}{2}+1\right)}
$$




\section{Modeling the TCP throughput.}

$\square$ Based on previous results we can derive an expresion for TCP throughput based on Padhye's model:

$$
\begin{gathered}
B=\frac{P_{l}\left(E[Y]+Q * E\left[Y_{T O}\right]\right)}{E[A]+Q * E\left[A_{T O}\right]} \\
=\frac{P_{l}\left(\frac{1-p_{l o s t}}{p_{l o s t}}+N_{C W}+Q \frac{1}{1-p_{l o s t}}\right)}{T_{R T T}\left(N_{C W}+1\right)+Q T_{R T O} \frac{f\left(p_{\text {lost }}\right)}{1-p_{\text {lost }}}}
\end{gathered}
$$

$\square$ Where $Y$ is the number of packets and $A$ the duration of the RTT. 


\section{Assessing the impact of BS mac queve length}

$\square$ From the performance model, when BS queue length is big enough, TCP throughput is limited by the sending rate of the user:

$$
\lim _{Q_{B S} \rightarrow \infty} B_{k}=\frac{3}{4} \frac{r_{k}}{N}
$$

$\square$ Besides:

- When BS queve size is small, and link is underutilized.

$\square$ When queve size large enough, TCP throughput is constrained by scheduled transmitting rate and delay increases. 


\section{Performance Model: Uplink Delay}

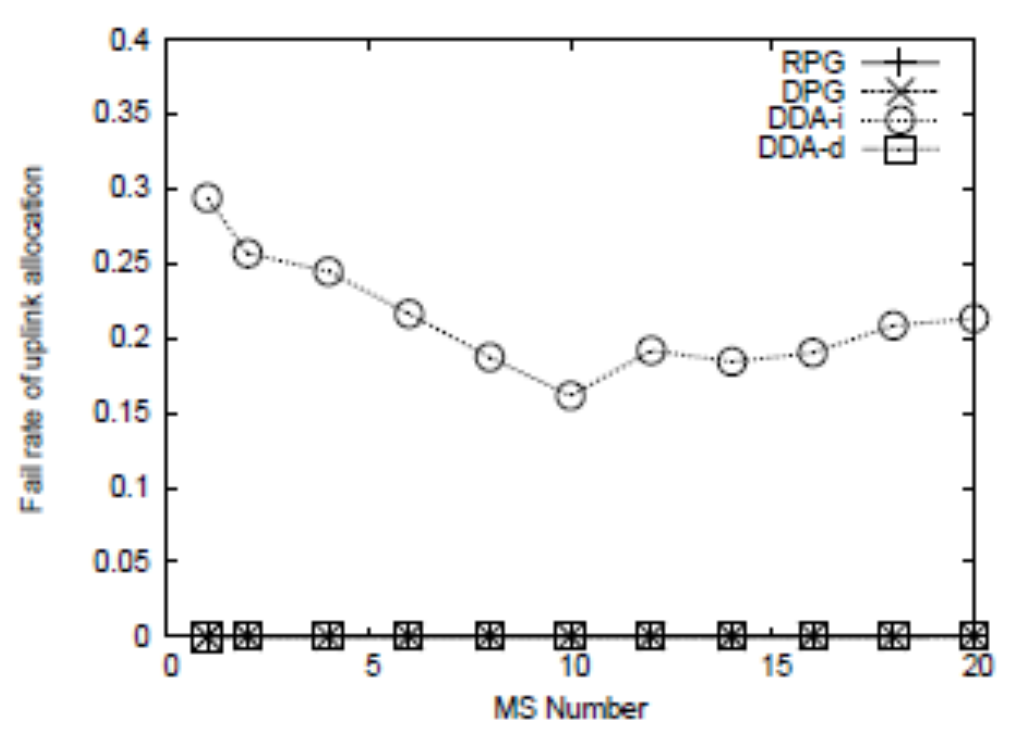

(a) Failure rate $q$ vs. MS num

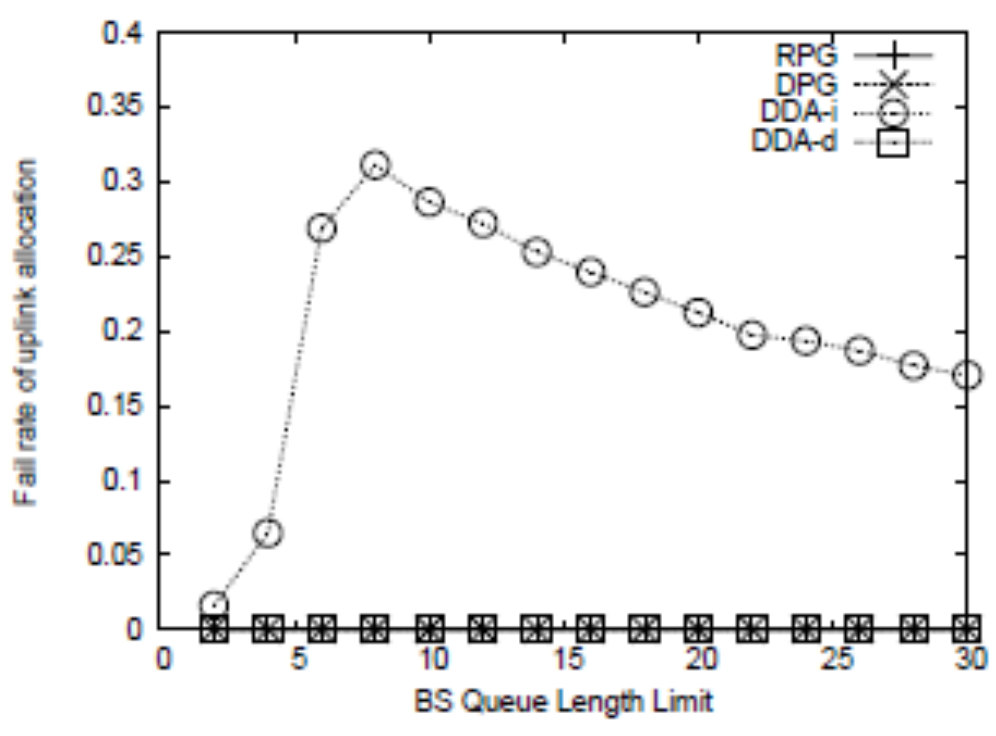

(b) Failure rate $q$ vs. BS Queue Length Limit

We've obtained by simulation differences among bandwidth perception schemes that can be characterized by bandwidth allocation failure rate q. 


\section{Simulation Results}

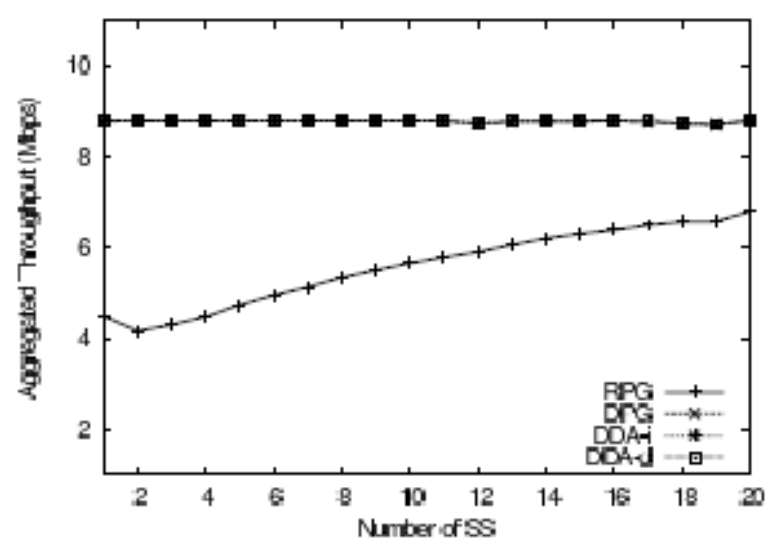

(a) Aggregated Throughput

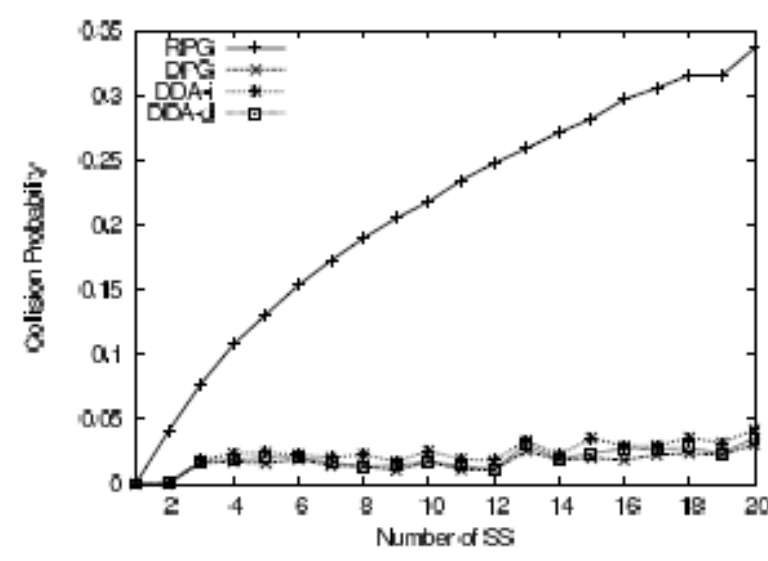

(b) BW-REQ Collision Probability

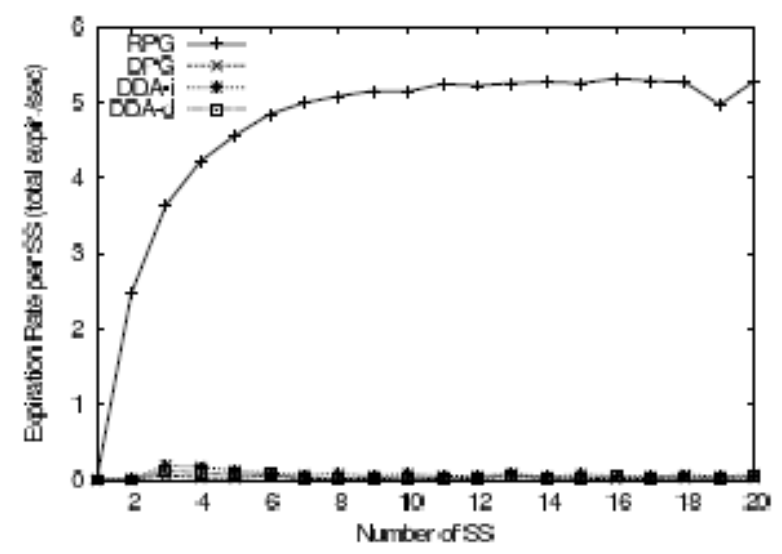

(c) T16 Expiration Rate per SS

Figure 10. Upload-only traffic scenario, using one aggregate bandwidth request per 50 incremental bandwidth requests (BW-REQs).

\section{$\square$ Uplink performance}




\section{Simulation Results}

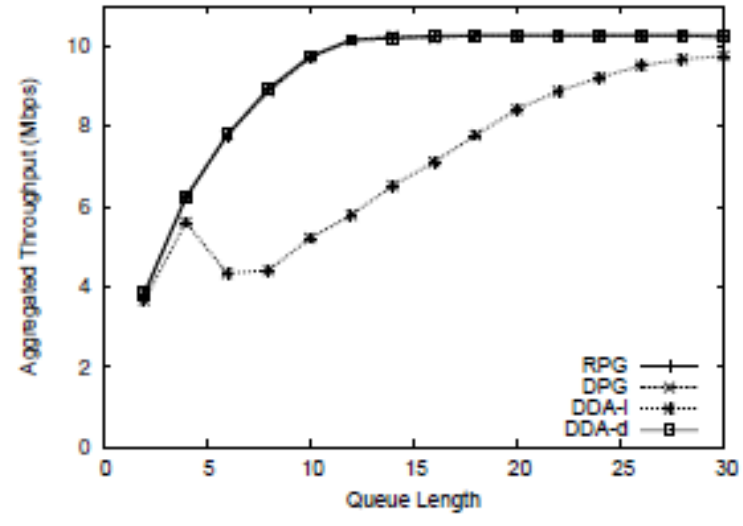

(a) Aggregated Throughput

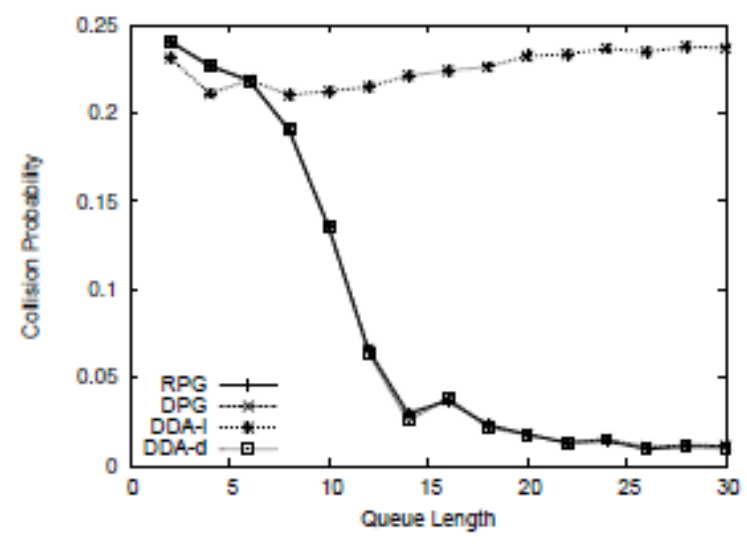

(b) BW-REQ Collision Probability

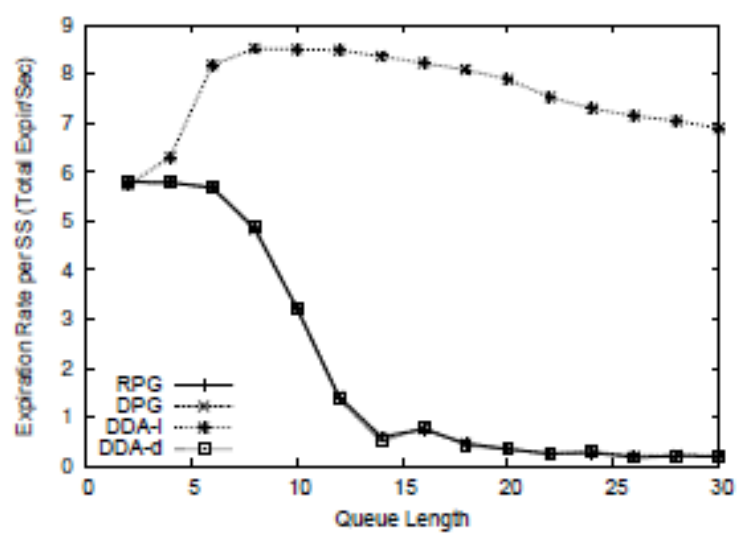

(c) T16 Expiration Rate per SS

Figure 11. Downlink only traffic, Performance with different queue length limit, MS number is 10 .

$\square$ Impacts of MAC queue length 


\section{Simulation Results \\ Impacts of wireless losses}

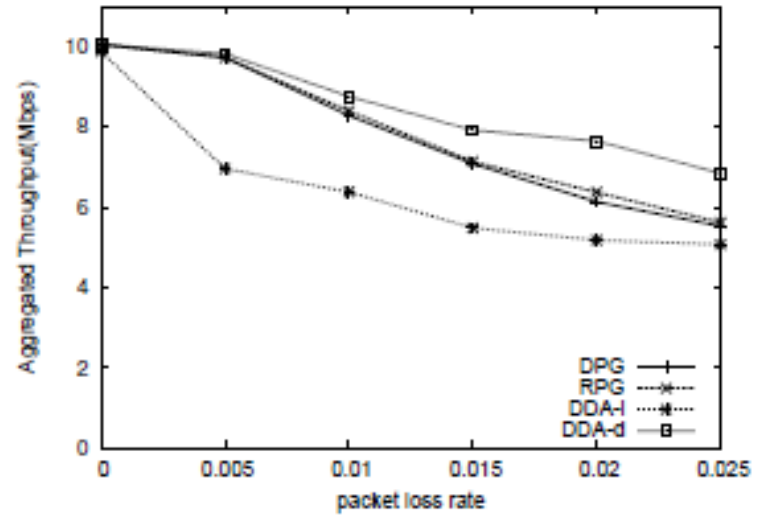

(a) Aggregated Throughput

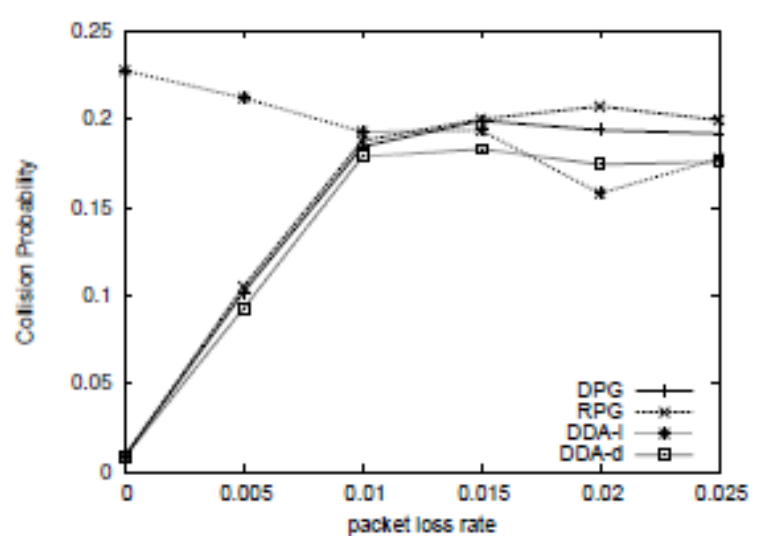

(b) BW-REQ Collision and Wirless Loss Probability

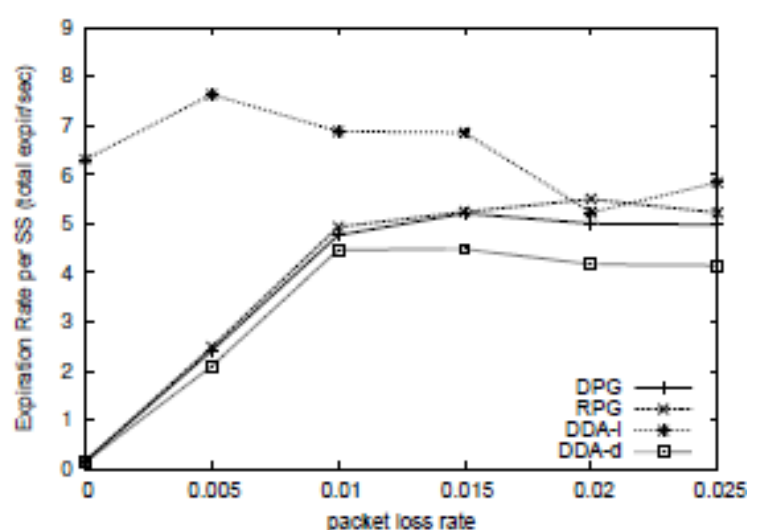

(c) T16 Expiration Rate per SS

Figure 12. Downlink onlv traffic. Performance with different wireless loss rate. MS number is 10 . 


\section{Aggregated Throughput vs. Number of MS}

\section{Model Based}

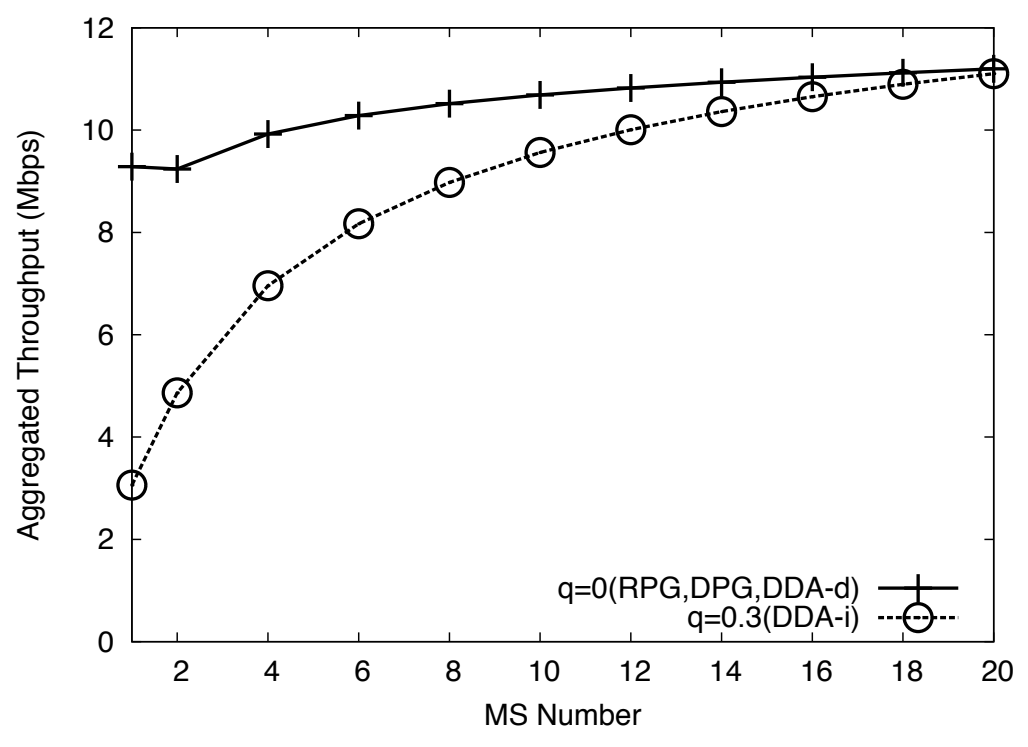

\section{Simulation Results}

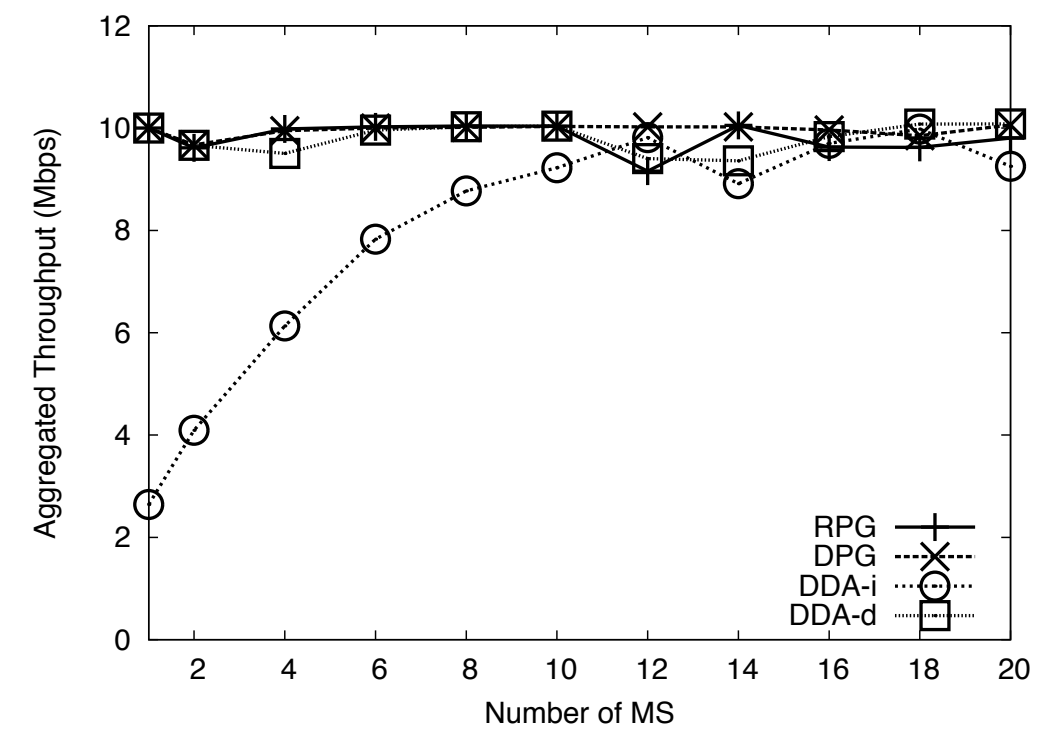




\section{Aggregated Throughput vs. BS queue length}
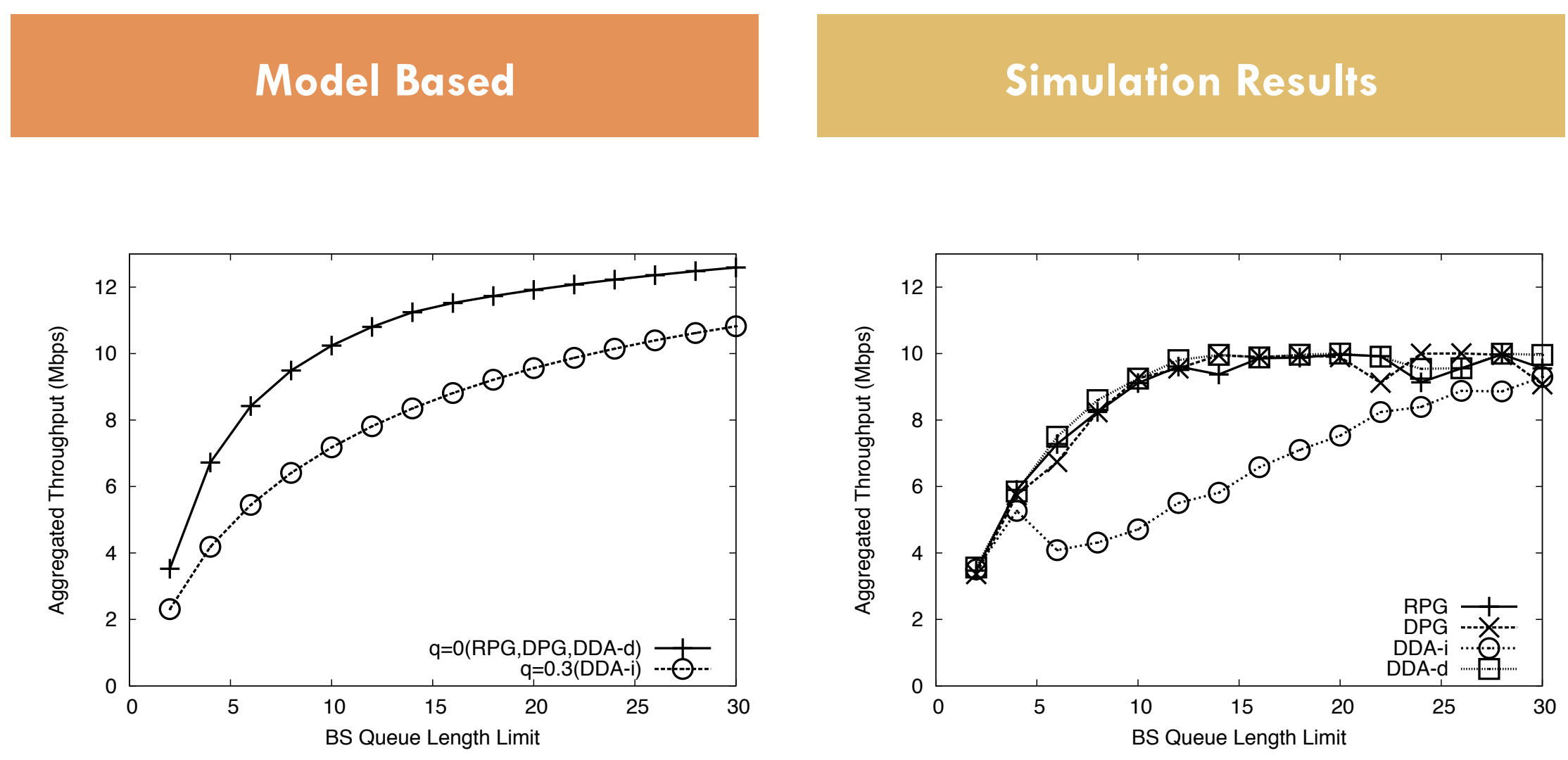


\section{Aggregated throughput vs. T1 6 timer}
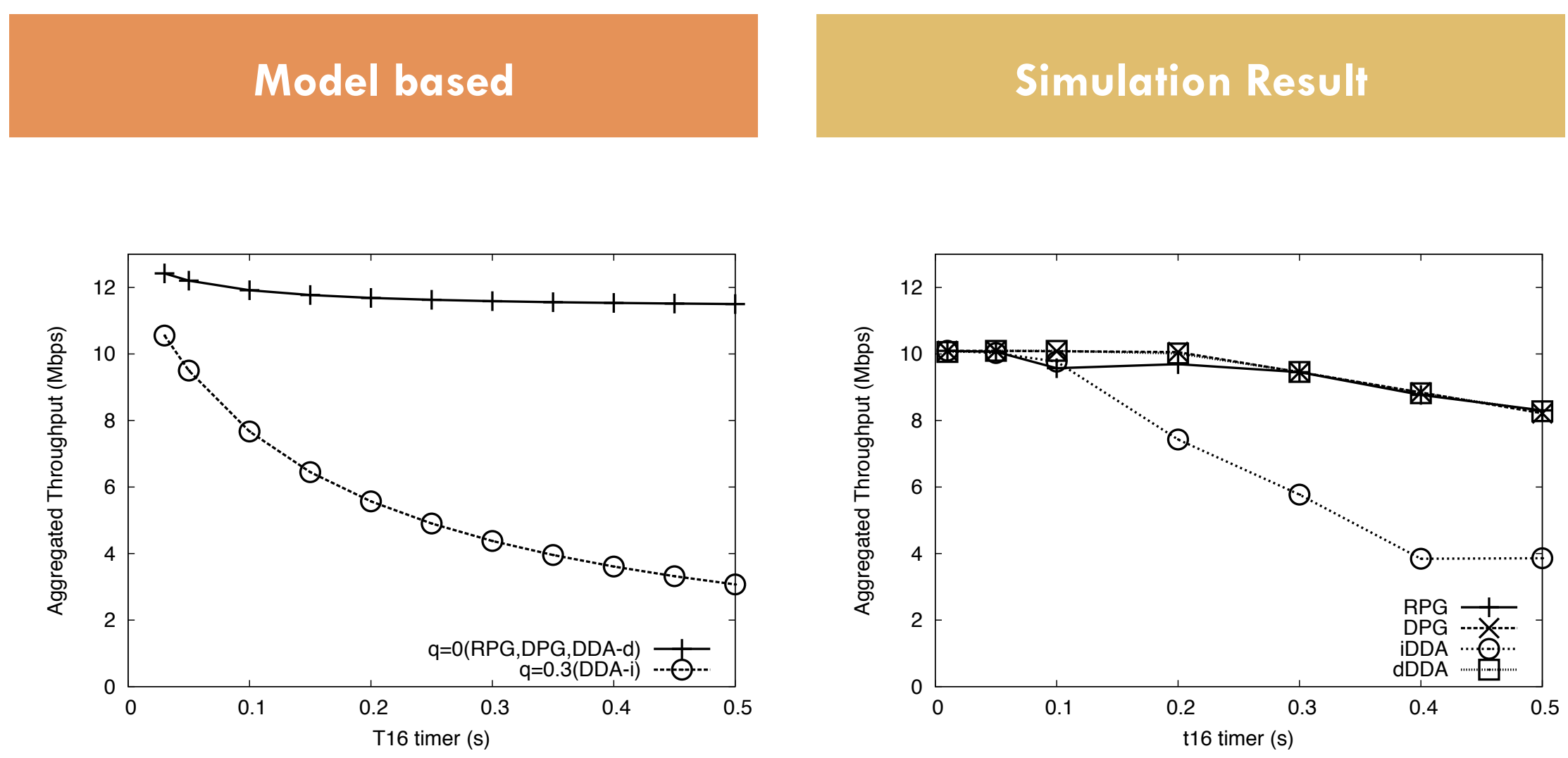


\section{Conclusion}

$\square$ Bandwidth request-grant mechanism is a critical subsystem

$\square$ BS can misperceive the bandwidth needs of SSs, affecting the TCP performance.

$\square$ The BRGM relies heavily on the BW-REQ treatment

$\square$ Deeper understanding of BW-REQ mechanism

$\square$ Built a model that takes into account BS MAC queve, SS number, T1 6 timer.

$\square$ We have synthesized the degree of desynchronization and modeled its impact of TCP performance. 


\section{Future Work}

$\square$ Work on a extended version of the DDA-d mechanism that dynamically delays treatment of BW-REQs.

$\square$ Give precise rules on setting queue size and $T 16$ timer (i.e., depending on the system's load).

$\square$ Investigate the impact of ' $q$ ' on timeout events of TCP. 
Thank you.

Questions? 